\title{
Using LMS tables to determine waist circumference and waist-to-height ratios in Colombian children and adolescents: the FUPRECOL study
}

Robinson Ramírez-Vélez ${ }^{1 *}$, Javier Moreno-Jiménez', Jorge Enrique Correa-Bautista ${ }^{1}$, Javier Martínez-Torres ${ }^{1}$, Katherine González-Ruiz², Emilio González-Jiménez ${ }^{3,4}$, Jacqueline Schmidt-RioValle ${ }^{3,4}$, Felipe Lobelo ${ }^{5}$ and Antonio Garcia-Hermoso ${ }^{6}$

\begin{abstract}
Background: Waist circumference (WC) and waist-to-height ratio (WHtR) are often used as indices predictive of central obesity. The aims of this study were: 1) to obtain smoothed centile charts and LMS tables for WC and WHtR among Colombian children and adolescents; 2 ) to evaluate the utility of these parameters as predictors of overweight and obesity.

Method: A cross-sectional study was conducted of a sample population of 7954 healthy Colombian schoolchildren [3460 boys and 4494 girls, mean age 12.8 ( \pm 2.3 ) years]. Weight, height, body mass index (BMI), WC and WHtR were measured, and percentiles were calculated using the LMS method (Box-Cox, median and coefficient of variation). Appropriate cut-off points of WC and WHtR for overweight and obesity, according to International Obesity Task Force definitions, were selected using receiver operating characteristic (ROC) analysis. The discriminating power of WC and WHtR is expressed as area under the curve (AUC).

Results: Reference values for WC and WHtR are presented. Mean WC increased and WHtR decreased with age for both genders. A moderate positive correlation was observed between WC and BMI $(r=0.756, P<0.01)$ and between WHtR and BMI $(r=0.604, P<0.01)$. ROC analysis revealed strong discrimination power in the identification of overweight and obesity for both measures in our sample population. Overall, WHtR was a slightly better predictor of overweight/obesity (AUC 95\% Cl 0.868-0.916) than WC (AUC 95\% Cl 0.862-0.904).

Conclusion: This paper presents the first sex and age-specific WC and WHtR percentiles for Colombian children and adolescents aged 9.0-17.9 years. The LMS tables obtained, based on Colombian reference data, can be used as quantitative tools for the study of obesity and its comorbidities.
\end{abstract}

Keywords: Central obesity, Reference values, Anthropometric indices

\footnotetext{
* Correspondence: robin640@hotmail.com; robinson.ramirez@urosario.edu.co

${ }^{1}$ Centro de Estudios para la Medición de la Actividad Física (CEMA). Escuela

de Medicina y Ciencias de la Salud, Universidad del Rosario, Cra. 24 No. 63C -

69, Bogotá D.C, Colombia

Full list of author information is available at the end of the article
}

(c) The Author(s). 2017 Open Access This article is distributed under the terms of the Creative Commons Attribution 4.0 International License (http://creativecommons.org/licenses/by/4.0/), which permits unrestricted use, distribution, and reproduction in any medium, provided you give appropriate credit to the original author(s) and the source, provide a link to the Creative Commons license, and indicate if changes were made. The Creative Commons Public Domain Dedication waiver (http://creativecommons.org/publicdomain/zero/1.0/) applies to the data made available in this article, unless otherwise stated. 


\section{Background}

The prevalence of overweight and obesity is a global public health problem [1]. Recesntly studies indicate that increased body weight and inadequate body fat distribution are associated with adverse health problems, including hypertension, cardiovascular disease, metabolic disorders, and asthma, as well as multiple malignancies [2-4]. International organisations and epidemiological cross-sectional studies have suggested that individuals with a hight porcentage of body fat in the abdominal region are at greater risk of developing metabolic syndrome [5-9]. Body fat in general and abdominal fat in particular are often studied using anthropometric indicators such as waist circumference (WC), waist-to-height ratio (WHtR) and body mass index (BMI) $[8,10,11]$. These indicators are simple to measure and calculate, inexpensive and applicable to a large number of individuals in epidemiological studies and clinical practice [10-14].

The two most widely used definitions of abdominal fat are those of the National Cholesterol Education Program Adult Treatment Panel III (NCEP: ATPIII) and of the International Diabetes Federation (IDF). Both focus on WC, as a surrogate measure of central obesity [5, 14]. Another useful anthropometric indicator of body fat deposits is the waist-to-height ratio (WHtR), also termed the index of central obesity [3, 15-17]. Ashwell et al. [10], in a meta-analysis, confirmed that measures of abdominal obesity, especially WHtR, provide a superior tool for discriminating obesity-related cardiometabolic risk, compared with BMI.

Colombia, like other low and middle-income countries in Latin America and also in Africa, is undergoing a situation of nutritional transition, with a growing prevalence of overweight and obesity among the population. Accordingly, criteria should be established to identify populations at high risk of presenting excessive body fat, so that preventive interventions can be designed and implemented [18-20].

Ethnic and environmental differences probably influence body proportions, and so national references would be useful to control for variations between populations. Cut-off values and percentiles for WHtR and WC are available for children and adolescents in various countries [21-26], but not in Colombia. Although studies have been conducted of adolescent populations in Colombia, using LMS methods, and have obtained representative percentiles, by age and sex, for certain anthropometric indicators (percentage of body fat, BMI, WC and waist/hip ratio) [27, 28], these studies were based on small samples, and more extensive studies are needed to better characterise the child and adolescent population of Colombia.
Taking these considerations into account, the aims of this study were to establish smoothed centile charts and LMS tables for WC and WHtR in a population of Colombian children and adolescents and to evaluate the utility of these parameters as predictors of overweight and obesity.

\section{Methods}

\section{Study design and sample population}

This cross-sectional study was conducted among a sample population consisting of healthy Colombian children and adolescents. In this country, data on young people's weight, height and physical activity, among other parameters, are recorded in public health monitoring systems [29]. In this respect, the FUPRECOL study (In Spanish: [Asociación de la fuerza prensil con manifestaciones de riesgo cardiovascular tempranas en niños y adolescentes colombianos], Association between grip strength and early signs of cardiovascular risk in Colombian children and adolescents) $[20,28,30]$ was performed to determine levels of physical fitness among children and adolescents in Colombia, and to determine their relation with the general prevalence of cardiovascular risk factors in this population. The FUPRECOL study assessments were conducted during 2014-2015.

The sample in the present study consisted of 7954 healthy Colombian schoolchildren with an average age of $12.7( \pm 2.4)$ years, with 3460 boys and 4494 girls. This sample represented $72.3 \%$ of the sample size of the primary FUPRECOL study, which included 11,000 schoolchildren aged from 9 to 14 years, from families with a low socioeconomic status and attending Statefunded schools in Bogotá. The present study included only those participants who completed the same tests and were subjected to the same methodological approach for anthropometric variables.

In recruiting the sample, 27 public elementary and high schools (grades 5-11) were selected in the capital district of Bogotá (Cundinamarca Department, Andean region) [31]. These schools were selected taking into account the existence of collaboration agreements with our research centre, and so were selected mainly for pragmatic, budgetary and logistic reasons. Thus, convenience sampling was performed.

All the children in our study population were of low-middle socioeconomic status (1-3 on a scale of 1-6 defined by the Colombian government). The sample was grouped by age in 1-year increments and sex. The significance level was set to 0.05 , and the required power was set to at least 0.80 . Power calculations were based on the mean values for overweight and obesity among the first 200-400 participants in the ongoing data collection (range: $26-32 \mathrm{~kg} / \mathrm{m}^{2}$ ), 
with a group SD of approximately $5.2 \mathrm{~kg} / \mathrm{m}^{2}$. Finally, the sample size was calculated to be approximately 250-500 participants per group. Exclusion factors included a clinical diagnosis of cardiovascular disease, diabetes mellitus 1 or 2, pregnancy, the use of alcohol or drugs, and, in general, the presence of any disease not directly associated with nutrition. Exclusion from the study was made effective a posteriori, without the students being aware of their exclusion.

\section{Measures}

Each participant underwent a complete anthropometric evaluation performed according to the International Society for the Advancement of Kinanthropometry [32]. Body weight was measured, using electronic scales (Tanita ${ }^{\circ}$ BC544, Tokyo, Japan) with a low technical error of measurement $($ TEM $=0.510 \%)$. Height $(\mathrm{Ht})$ was measured using a portable stadiometer ( $\mathrm{Seca}^{\circ} 274$, Hamburg, Germany; TEM $=0.019 \%)$. BMI was calculated as weight divided by height squared $\left(\mathrm{kg} / \mathrm{m}^{2}\right)$. Waist circumference was measured at the midpoint between the last rib and the iliac crest using a tape measure (Ohaus $^{\circ}$ 8004-MA, New Jersey, USA;
$\mathrm{TEM}=0.086 \%)[20]$. WHtR was calculated as the ratio of WC (in $\mathrm{cm}$ ) to $\mathrm{Ht}$ (in $\mathrm{cm}$ ). Overweight and obesity were defined as BMI above the age and sex-specific thresholds of the IOTF [33]. According to this definition, the group of subjects with overweight (the equivalent of BMI $\geq 25 \mathrm{~kg} / \mathrm{m}^{2}$ ) also contains those who are obese (the equivalent of $\mathrm{BMI} \geq 30 \mathrm{~kg} / \mathrm{m}^{2}$ ).

\section{Statistical analyses}

Anthropometric characteristics from the study sample are presented as mean and standard deviation (SD). Normality for selected variables was verified using histograms and Q-Q plots. Data were then split by sex, and a one-way ANOVA with post hoc tests (Tukey) was used to identify differences between age groups within sexes. Smoothed age and gender-specific table percentiles (3rd, 10th, 25th, 50th, 75th, 90th and 97th) were constructed for WC and WHtR via a penalised maximum likelihood approach. The following abbreviations are used: (1) M (median), (2) L (Box-Cox transformation) and (3) S (coefficient of variation). The associations between $\mathrm{WC}, \mathrm{WHtR}$ and $\mathrm{BMI}$ were tested by means of Pearson correlation coefficients. The relations between WC, WHtR and overweight/obesity

Table 1 Mean values (standard deviation, SD) for body weight (BW), height (Ht), body mass index (BMI), waist circumference (WC) and waist-to-height ratio (WHtR) for Colombian children and adolescents aged 9-17.9 years

\begin{tabular}{|c|c|c|c|c|c|c|}
\hline$\overline{\text { Sex }}$ & $n$ & Body weight (kg) & Height $(\mathrm{cm})$ & BMI $\left(\mathrm{kg} / \mathrm{m}^{2}\right)$ & WC (cm) & $\mathrm{WH} t \mathrm{R}$ \\
\hline \multicolumn{7}{|l|}{ Boys } \\
\hline 9 to 9.9 & 258 & $32.1(7.5)$ & $133.5(6.5)$ & $17.8(3.1)$ & $60.8(6.7)^{*}$ & $0.455(0.044)^{* *}$ \\
\hline 10 to 10.9 & 466 & $34.5(8.5)$ & $137.3(7.4)^{*}$ & $18.1(3.3)$ & $61.7(8.0)^{*}$ & $0.450(0.052)^{* *}$ \\
\hline 11 to 11.9 & 445 & $37.2(8.8)^{*}$ & $141.9(8.2)^{*}$ & $18.3(3.2)$ & $63.5(7.6)^{*}$ & $0.448(0.047)^{* *}$ \\
\hline 12 to 12.9 & 404 & $41.3(9.1)^{*}$ & $147.1(8.2)^{*}$ & $18.9(3.2)$ & $64.7(7.5)^{*}$ & $0.440(0.047)^{* *}$ \\
\hline 13 to 13.9 & 401 & $46.0(9.8)^{*}$ & $153.5(9.3)^{*}$ & $19.4(3.3)^{* *}$ & $65.8(7.7)$ & $0.429(0.048)$ \\
\hline 14 to 14.9 & 443 & $50.0(9.7)^{*}$ & $158.9(9.1)^{* *}$ & $19.7(3.0)^{* *}$ & $67.1(7.1)$ & $0.423(0.043)^{* *}$ \\
\hline 15 to 15.9 & 426 & $54.4(9.7)^{*}$ & $163.3(8.9)^{* *}$ & $20.3(3.0)^{* *}$ & $69.2(6.7)$ & $0.424(0.042)^{* *}$ \\
\hline 16 to 16.9 & 365 & $57.7(8.7)^{* * *}$ & $166.7(7.2)^{* *}$ & $20.8(2.9)^{* *}$ & $70.6(7.1)^{* *}$ & $0.424(0.045)^{* *}$ \\
\hline 17 to 17.9 & 252 & $60.8(10.3)^{* *}$ & $168.1(7.4)^{* *}$ & $21.5(3.3)^{* *}$ & $72.1(7.4)^{* *}$ & $0.430(0.044)^{*}$ \\
\hline Total & 3460 & $45.5(13.0)^{*}$ & $151.9(14.1)^{* *}$ & $19.4(3.3)^{* *}$ & $66.0(8.1)^{* *}$ & $0.436(0.048)$ \\
\hline \multicolumn{7}{|l|}{ Girls } \\
\hline 9 to 9.9 & 308 & $32.1(7.4)$ & $134.6(7.6)$ & $17.6(3.0)$ & $59.3(6.6)$ & $0.441(0.041)$ \\
\hline 10 to 10.9 & 659 & $35.0(7.9)$ & 138.4 (7.6) & $18.1(3.0)$ & $60.9(7.4)$ & $0.439(0.047)$ \\
\hline 11 to 11.9 & 645 & $38.3(7.9)$ & $143.7(7.5)$ & $18.4(2.9)$ & $62.1(6.7)$ & $0.432(0.044)$ \\
\hline 12 to 12.9 & 549 & $42.8(8.6)$ & $148.5(7.3)$ & $19.3(3.0)$ & $63.2(6.9)$ & $0.426(0.044)$ \\
\hline 13 to 13.9 & 472 & $47.4(9.0)$ & $152.4(6.3)$ & $20.3(3.2)$ & $65.2(7.3)$ & $0.427(0.046)$ \\
\hline 14 to 14.9 & 609 & $51.0(8.9)$ & $154.6(6.5)$ & $21.3(3.3)$ & $67.3(8.0)$ & $0.436(0.052)$ \\
\hline 15 to 15.9 & 504 & $52.7(8.6)$ & $155.7(6.8)$ & $21.7(3.1)$ & $68.5(7.1)$ & $0.440(0.046)$ \\
\hline 16 to 16.9 & 450 & $53.9(8.6)$ & $156.4(5.8)$ & $22.0(3.1)$ & $68.7(7.7)$ & $0.440(0.049)$ \\
\hline 17 to 17.9 & 296 & $55.1(9.3)$ & $156.8(6.5)$ & $22.4(3.6)$ & $69.5(7.7)$ & $0.444(0.050)$ \\
\hline Total & 4494 & 44.8 (11.5) & $148.7(10.1)$ & $20.0(3.5)$ & $64.8(8.0)$ & $0.436(0.047)$ \\
\hline
\end{tabular}

Data values are reported as mean and standard deviation (SD) 
as defined by IOTF [33] were investigated using receiver operating characteristic (ROC) curves. Cut-off values were derived mathematically from the ROC curves, using the point on the ROC curve with the lowest value for the formula: (1-sensitivity $)^{2}+(1 \text {-specificity })^{2}$. The positive likelihood ratio LR (+) and the negative likelihood ratio LR (-) were also determined. Descriptive statistics were calculated with SPSS 21.0 (SPSS Inc. Chicago, IL, USA). Statistical significance was set at $P<0.05$.

\section{Results}

Descriptive statistics for weight, $\mathrm{Ht}, \mathrm{BMI}, \mathrm{WC}$ and WHtR by age group are presented in Table 1 . The corresponding percentiles are listed in Table 2 (WC) and Table 3 (WHtR). Mean BMI values were comparable in both sexes, and the prevalence of overweight was $25.0 \%$ (95\% CI: $23.5-26.6 \%)$ and $15.8 \%$ (95\% CI: $14.4-17.35 \%)$ in girls and boys, respectively. The prevalence of obesity was 9.9\% (95\% CI: 8.9-11.0\%) and 7.5\% (95\% CI: 6.5$8.5 \%)$ in girls and boys, respectively. Mean WC increased and WHtR decreased with age for both genders. In both sexes, there was a moderate positive correlation between WC and BMI $(r=0.756, P<0.01)$ and between WHtR

Table 2 Smoothed age- and sex-specific percentile of WC (cm) for Colombian children and adolescents aged 9-17.9 years

\begin{tabular}{|c|c|c|c|c|c|c|c|c|c|c|}
\hline & $n$ & M & SD & $P_{3}$ & $P_{10}$ & $P_{25}$ & $P_{50}$ & $P_{75}$ & $P_{90}$ & $P_{97}$ \\
\hline \multicolumn{11}{|l|}{ Boys } \\
\hline 9 to 9.9 & 258 & 60.8 & 6.7 & 51.2 & 54.0 & 56.2 & 59.4 & 64.3 & 69.9 & 7 \\
\hline 10 to 10.9 & 466 & 61.7 & 8.0 & 51.6 & 53.5 & 56.7 & 60.3 & 65.9 & 72.4 & 79 \\
\hline 11 to 11.9 & 445 & 63.5 & 7.6 & 53.4 & 56.0 & 58.1 & 62.0 & 67.0 & 75.5 & 1 \\
\hline 12 to 12.9 & 404 & 64.7 & 7.5 & 54.0 & 56.5 & 60.0 & 63.3 & 69.0 & 75.7 & 83 \\
\hline 13 to 13.9 & 401 & 65.8 & 7.7 & 54.6 & 58.5 & 61.2 & 64.6 & 69.3 & 75.3 & 85.5 \\
\hline 14 to 14.9 & 443 & 67.1 & 7.1 & 56.4 & 60.0 & 62.5 & 65.7 & 70.6 & 76.7 & 86.2 \\
\hline 15 to 15.9 & 426 & 69.2 & 6.7 & 59.1 & 62.0 & 64.5 & 68.1 & 72.1 & 78.3 & 8 \\
\hline 16 to 16.9 & 365 & 70.6 & 7.1 & 59.5 & 63.2 & 66.6 & 70.0 & 74.0 & 78.6 & 81 \\
\hline 17 to 17.9 & 252 & 72.1 & 7.4 & 61.0 & 64.7 & 67.6 & 71.2 & 75.4 & 82.3 & 887 \\
\hline Total & 3460 & 66.0 & 8.1 & 53.6 & 56.5 & 60.5 & 65.3 & 70.5 & 76.5 & 84 \\
\hline \multicolumn{11}{|l|}{ Girls } \\
\hline 9 to 9.9 & 308 & 59.3 & 6.6 & 50.1 & 52.0 & 54.4 & 58.0 & 63.4 & 68.8 & 14.3 \\
\hline 10 to 10.9 & 659 & 60.9 & 7.4 & 50.8 & 53.0 & 55.8 & 59.6 & 64.6 & 71.0 & 79.0 \\
\hline 11 to 11.9 & 645 & 62.1 & 6.7 & 52.5 & 54.8 & 57.4 & 60.8 & 66.0 & 71.0 & 76.7 \\
\hline 12 to 12.9 & 549 & 63.2 & 6.9 & 53.0 & 55.8 & 58.2 & 61.9 & 67.0 & 72.5 & 79.1 \\
\hline 13 to 13.9 & 472 & 65.2 & 7.3 & 53.6 & 57.1 & 60.3 & 64.3 & 69.4 & 74.3 & 82.0 \\
\hline 14 to 14.9 & 609 & 67.3 & 8.0 & 55.2 & 59.0 & 62.5 & 66.9 & 72.0 & 77.0 & 82 \\
\hline 15 to 15.9 & 504 & 68.5 & 7.1 & 57.0 & 60.5 & 64.2 & 67.5 & 72.3 & 77.0 & 86.0 \\
\hline 16 to 16.9 & 450 & 68.7 & 7.7 & 57.3 & 60.7 & 63.8 & 68.0 & 72.9 & 78.3 & 85 \\
\hline 17 to 17.9 & 296 & 69.5 & 7.7 & 58.0 & 61.0 & 64.5 & 68.5 & 73.3 & 79.4 & 3.9 \\
\hline Total & 4494 & 64.8 & 8.0 & 52.2 & 55.5 & 59.0 & 64.0 & 69.5 & 75.1 & 81.9 \\
\hline
\end{tabular}

and BMI $(r=0.604, P<0.01)$.

ROC analysis showed that both WC and WHtR had a high discriminating power to detect IOTF ovsserweight and obesity (Figs. 1 and 2). With respect to overweight among the boys in the study population, the cut-off point value of $62.7 \mathrm{~cm}$ for WC provided a sensitivity of $89.8 \%$, a LR $(+)$ value of 3.52 , specificity of $74.5 \%$ and LR $(-)$ value of 0.14 . In girls, the cut-off point value of $62.8 \mathrm{~cm}$ for WC provided a sensitivity of $82.1 \%$, a LR $(+)$ value of 4.72 , specificity of $82.6 \%$ and a LR $(-)$ value of 0.22 . For obesity in the boys, the cut-off value of $67.9 \mathrm{~cm}$ for WC provided a sensitivity of $87.0 \%$, a LR $(+)$ value of 5.06 , specificity of $82.8 \%$ and a LR (-) value of 0.16 . In the girls, the cut-off value of $65.9 \mathrm{~cm}$ for WC provided a sensitivity of $87.0 \%$, a LR $(+)$ value of 5.06 , specificity of $82.8 \%$ and a LR (-) value of 0.16 (Fig. 1 and Table 4). The ROC curve for WHtR was also obtained, using a cut-off value of 0.459 (Fig. 2 and Table 4). For overweight, with this cutoff point, in the boys the sensitivity was $78.2 \%$, the LR (+) 5.28 , the specificity $85.2 \%$ and the LR (-) 0.26 . In the girls, the cut-off value was 0.436 , the sensitivity $84.6 \%$, the LR $(+) 3.83$, the specificity $77.9 \%$ and the LR (-) 0.20 . For obesity in the boys, the cut-off value of 0.485 was used, producing a sensitivity of $83.5 \%$, LR (+) 6.05 , specificity $86.2 \%$ and LR (-) 0.19 . In the girls, the cut-off value was 0.472 , producing a sensitivity of $79.3 \%$, LR (+) 7.02 , specificity $88.7 \%$ and LR (-) 0.23 .

\section{Discussion}

This paper provides the first age and sex-specific WC and WHtR percentiles to be determined for Colombian children and adolescents (aged 9.0-17.9 years). These results can be used as a baseline for long-term health monitoring in rural and urban areas. The participants' body weight increased with age, as was to be expected; moreover, this was in line with the findings of previous studies [34, 35]. In our sample, the girls aged 9.013.9 years had higher mean $\mathrm{Ht}$ values than the boys of the same age. According to Cousiminer et al. [36], this increase in $\mathrm{Ht}$ could be related to physical and sexual development, which generally occurs earlier in girls, as has been reported elsewhere $[37,38]$.

The boys and girls in our sample had similar mean BMI values, although the prevalence of overweight and obesity was higher among the girls, which corroborates previous findings [27, 39-41]. Following Hirschler et al. [23], who studied a population of indigenous children in Argentina, we also found (as expected) that mean WC values increased with age. Moreover, studies have shown that the distribution pattern of subcutaneous fat varies with age 
Table 3 Smoothed age- and sex-specific percentile values of WHtR for Colombian children and adolescents aged 9-17.9 years

\begin{tabular}{|c|c|c|c|c|c|c|c|c|c|c|}
\hline & $n$ & $M$ & SD & $P_{3}$ & $P_{10}$ & $P_{25}$ & $P_{50}$ & $P_{75}$ & $P_{90}$ & $P_{97}$ \\
\hline \multicolumn{11}{|l|}{ Boys } \\
\hline 9 to 9.9 & 258 & 0.455 & 0.044 & 0.395 & 0.409 & 0.424 & 0.447 & 0.483 & 0.516 & 0.553 \\
\hline 10 to 10.9 & 466 & 0.450 & 0.052 & 0.383 & 0.398 & 0.418 & 0.442 & 0.477 & 0.519 & 0.567 \\
\hline 11 to 11.9 & 445 & 0.448 & 0.047 & 0.374 & 0.399 & 0.417 & 0.438 & 0.472 & 0.513 & 0.553 \\
\hline 12 to 12.9 & 404 & 0.440 & 0.047 & 0.373 & 0.390 & 0.409 & 0.429 & 0.461 & 0.509 & 0.557 \\
\hline 13 to 13.9 & 401 & 0.429 & 0.048 & 0.370 & 0.385 & 0.401 & 0.419 & 0.446 & 0.489 & 0.550 \\
\hline 14 to 14.9 & 443 & 0.423 & 0.043 & 0.362 & 0.381 & 0.394 & 0.413 & 0.443 & 0.483 & 0.533 \\
\hline 15 to 15.9 & 426 & 0.424 & 0.042 & 0.367 & 0.379 & 0.396 & 0.416 & 0.442 & 0.482 & 0.528 \\
\hline 16 to 16.9 & 365 & 0.424 & 0.045 & 0.364 & 0.380 & 0.399 & 0.420 & 0.441 & 0.484 & 0.524 \\
\hline 17 to 17.9 & 252 & 0.430 & 0.044 & 0.370 & 0.386 & 0.402 & 0.421 & 0.453 & 0.491 & 0.530 \\
\hline Total & 3460 & 0.436 & 0.048 & 0.370 & 0.388 & 0.404 & 0.427 & 0.457 & 0.501 & 0.546 \\
\hline \multicolumn{11}{|l|}{ Girls } \\
\hline 9 to 9.9 & 308 & 0.441 & 0.041 & 0.378 & 0.394 & 0.413 & 0.435 & 0.465 & 0.495 & 0.541 \\
\hline 10 to 10.9 & 659 & 0.439 & 0.047 & 0.373 & 0.390 & 0.408 & 0.429 & 0.463 & 0.501 & 0.549 \\
\hline 11 to 11.9 & 645 & 0.432 & 0.044 & 0.370 & 0.386 & 0.402 & 0.427 & 0.456 & 0.491 & 0.531 \\
\hline 12 to 12.9 & 549 & 0.426 & 0.044 & 0.360 & 0.376 & 0.395 & 0.421 & 0.450 & 0.484 & 0.532 \\
\hline 13 to 13.9 & 472 & 0.427 & 0.046 & 0.352 & 0.376 & 0.398 & 0.424 & 0.452 & 0.482 & 0.537 \\
\hline 14 to 14.9 & 609 & 0.436 & 0.052 & 0.364 & 0.385 & 0.403 & 0.430 & 0.464 & 0.501 & 0.549 \\
\hline 15 to 15.9 & 504 & 0.440 & 0.046 & 0.366 & 0.387 & 0.411 & 0.435 & 0.468 & 0.498 & 0.538 \\
\hline 16 to 16.9 & 450 & 0.440 & 0.049 & 0.363 & 0.388 & 0.410 & 0.434 & 0.467 & 0.497 & 0.552 \\
\hline 17 to 17.9 & 296 & 0.444 & 0.050 & 0.371 & 0.389 & 0.410 & 0.434 & 0.473 & 0.512 & 0.562 \\
\hline Total & 4494 & 0.436 & 0.047 & 0.365 & 0.385 & 0.405 & 0.429 & 0.461 & 0.496 & 0.539 \\
\hline
\end{tabular}

$M$ mean, $S D$ standard deviation, $P$ percentile

[41-44], with a tendency for fat to be deposited in the central area of the body instead of in peripheral areas, which heightens the risk of cardiovascular disease [43, 44].

Moreover, in line with previous studies $[45,46]$ our results found that for both males and females, mean WHtR values decreased with age, as was to be expected. In accordance with Wang et al. [47], in their study with children of Beijing (China), our results show a moderate correlation between WC and BMI in both boys and girls. Nonetheless, we agree with Smith and Haslam [48] that it would be useful to know which WC values are considered normal for each BMI level. This would permit corrective measures to be applied to persons with anomalous WC values, thus improving their cardiometabolic health. Our results also showed a positive correlation between WHtR and BMI, in both sexes, which is in line with the results of previous research $[49,50]$, according to which WHtR is an accurate indicator of cardiometabolic risk.

Regarding WC percentages for boys up to the age of 13.9 years, the 50th percentile presented higher values than those obtained by the same percentile of girls of the same age. This finding corroborates previous research using the LMS method [27]. After the age of 14 years, however, the girls in the 50th percentile had higher values than the boys. Differences between the sexes were less striking in the 97th percentile, although an upturn in WC values was observed in the boys aged 11.0-14.9 years, while no such variation occurred among the girls. Again, these results are indicative of sexual dimorphism in body composition [51].

Gender-related differences were also present in the WHtR: thus, boys aged 9.0-13.9 years had higher WHtR values than girls in the same age group. However, in the 14.0-17.9 year range, the tendency was reversed, and the girls had higher WHtR values in all percentiles. These results are in line with previous research on other sample populations $[52,53]$.

The ROC results showed that both WC and WHtR have a high discrimination power to detect overweight and obesity in our sample population of children and adolescents. The optimal cut-off value for WC among the boys with overweight was $73.8 \mathrm{~cm}$. This exceeded the cut-off values for adolescent girls and for children of both sexes. These results are similar to those obtained in previous research $[45,54]$. Concerning obesity, the 


\section{Waist circumference}
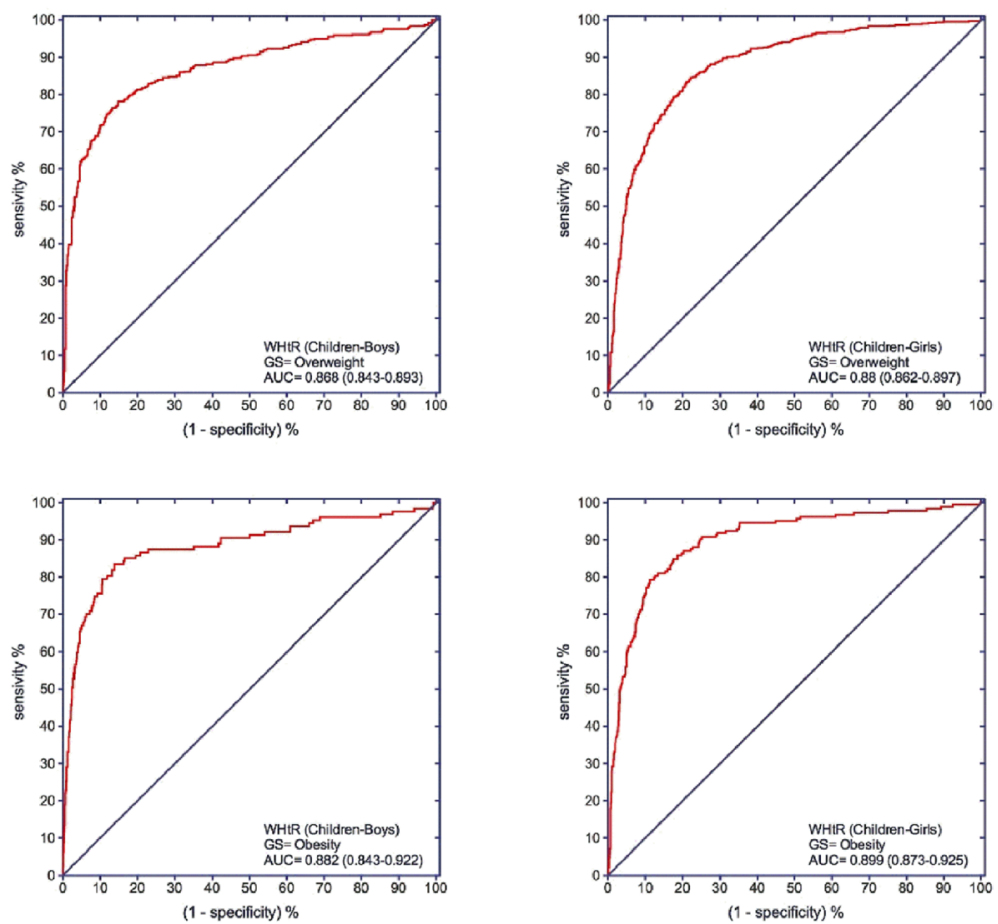

Waist-to-height ratio
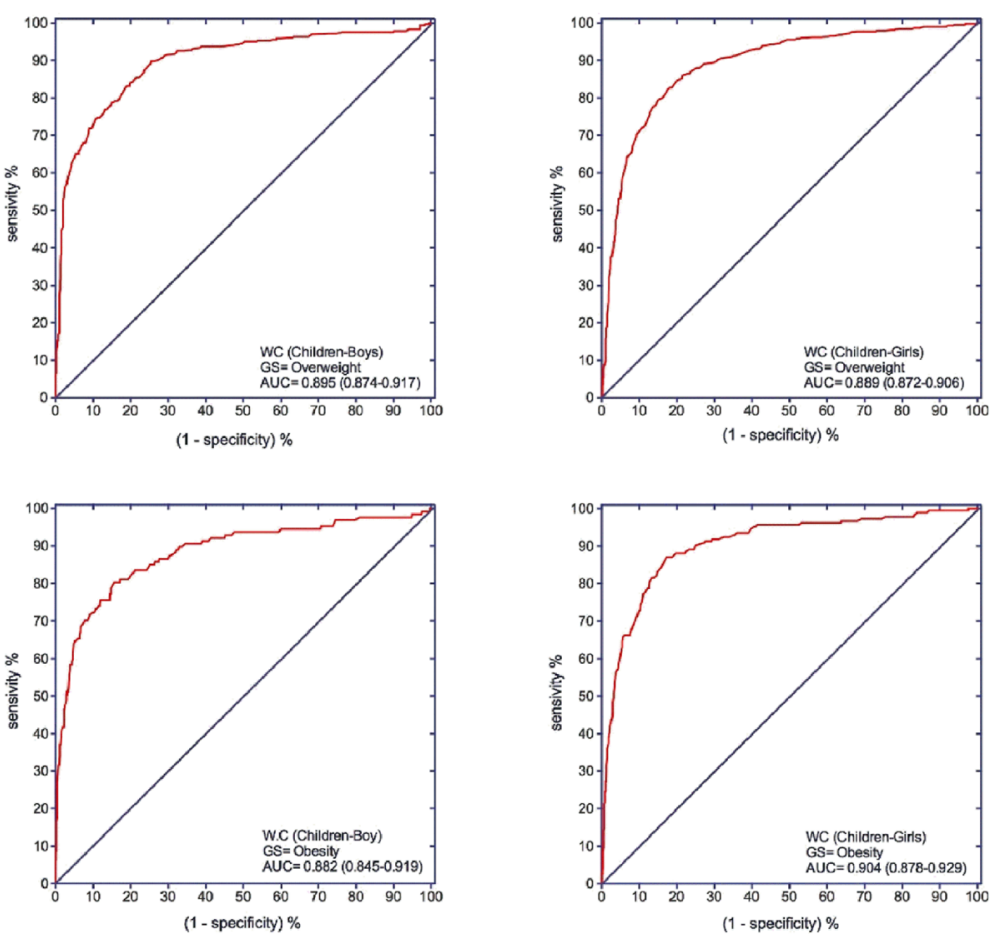

Fig. 1 Receiver operating characteristic (ROC) curve for WC and WHtR to detect overweight (top) or obesity (bottom) according to the IOFT criteria for Colombian children aged 9.0-12.9 years. GS: Gold standard; AUC: Area under the curve (95\% confidence interval) 
Waist circumference
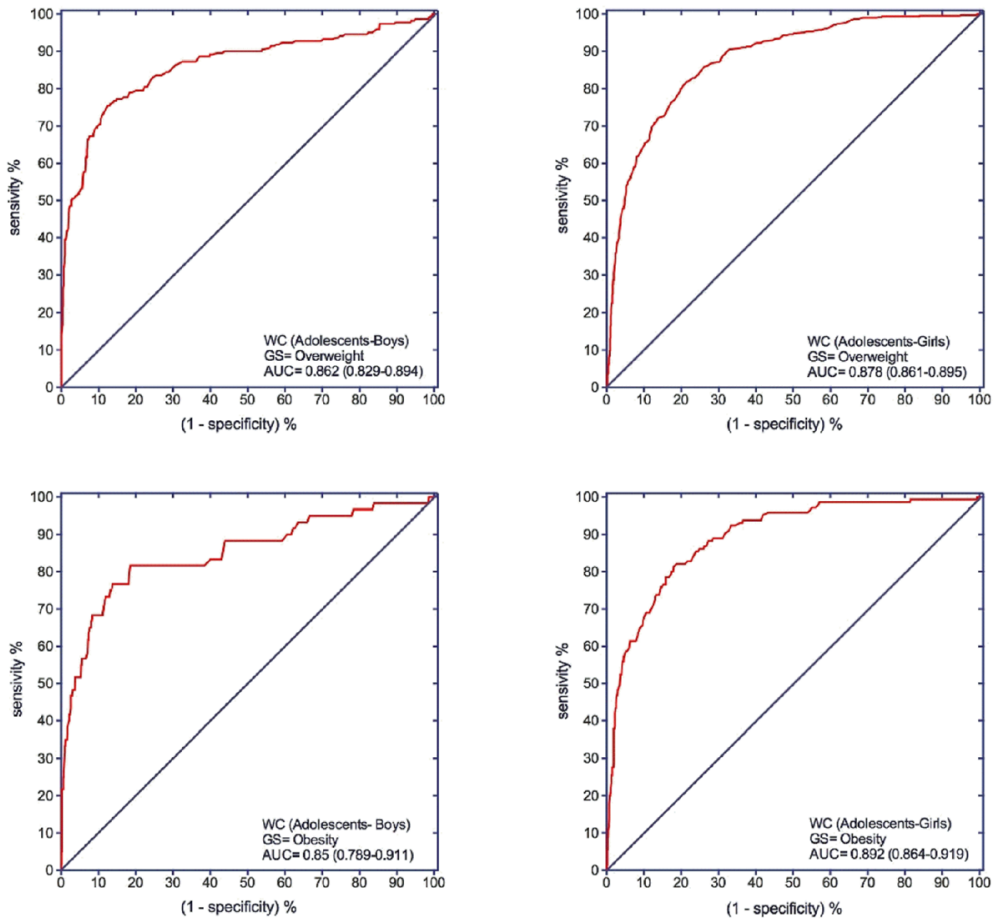

Waist-to-height ratio
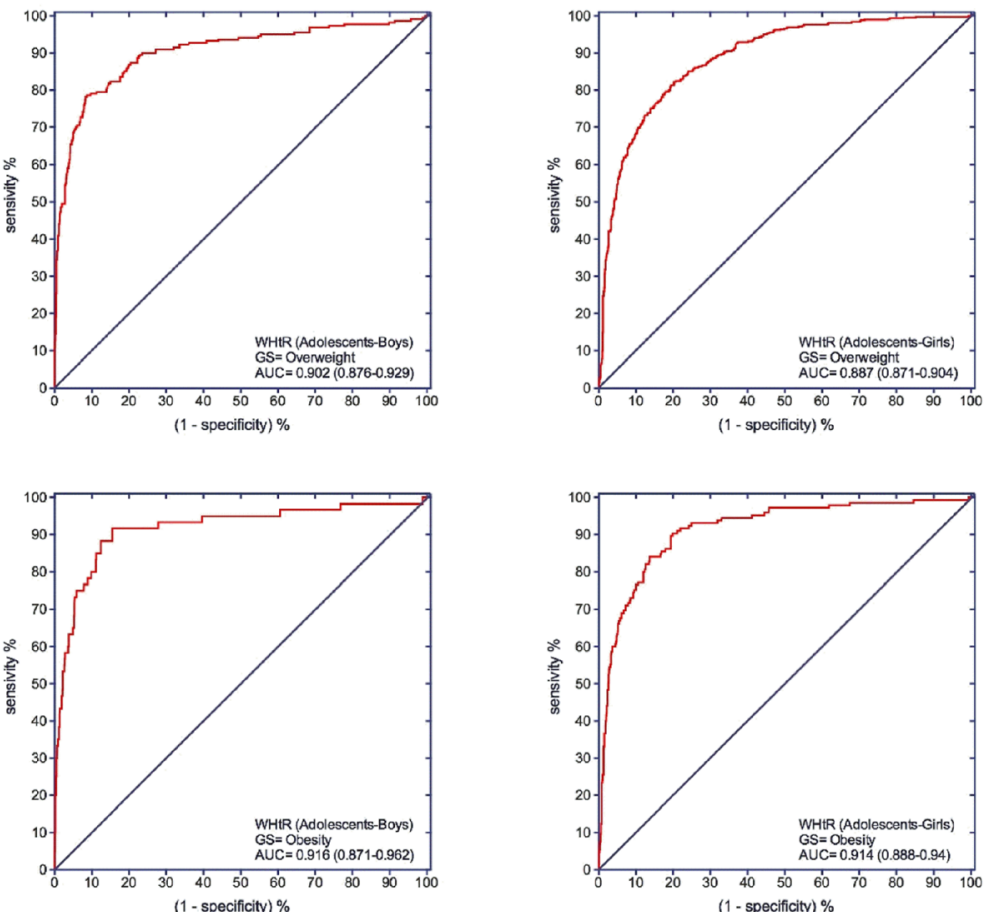

Fig. 2 Receiver operating characteristic (ROC) curve for WC and WHtR to detect overweight (top) or obesity (bottom) according to the IOFT criteria for Colombian adolescents aged 13.0-17.9 years. GS: Gold standard; AUC: Area under the curve (95\% confidence interval) 


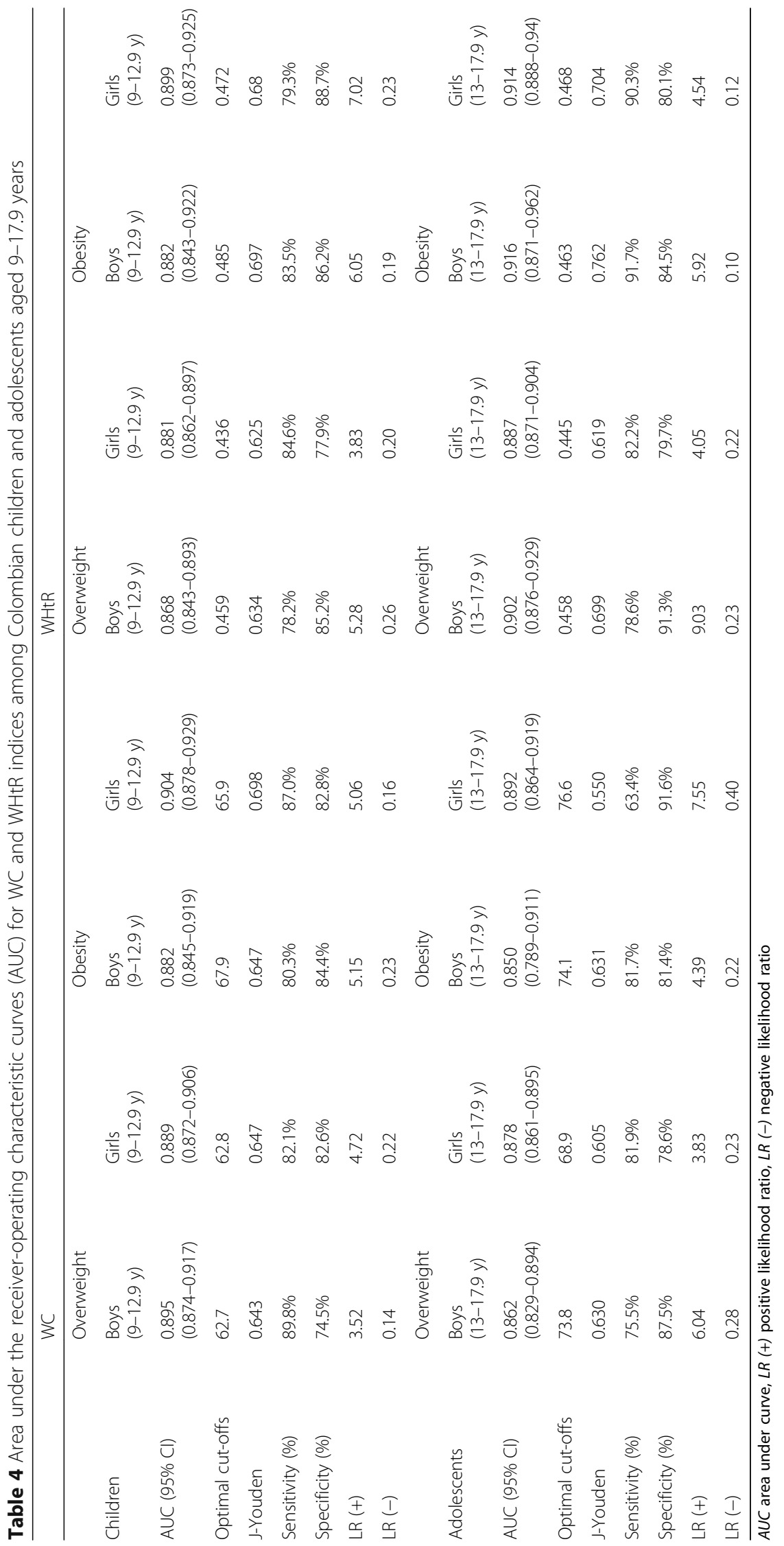


highest cut-off point was obtained for adolescent girls $(76.6 \mathrm{~cm})$, which coincides with previous international studies $[55,56]$.

The ROC analysis for WHtR in the overweight category produced similar cut-off values for children and adolescents of both sexes. For the obesity category, the values were also similar, especially in obese adolescents of both sexes. However, these values were lower than the 0.50 that Bacopoulou et al. [53] established as a cutoff point for obesity in Greek adolescent boys and girls. WC and WHtR $[8,10]$ are known to be better predictors of cardiovascular disease risk in children than BMI. Indeed, prospective and case-control studies have shown that even with a normal BMI, persons with a low degree of physical fitness are at increased risk of cardiovascular disease and premature death $[57,58]$. In Latin America, for example, Colombia has undergone rapid urbanisation and integration with world markets [20]. This has led to a worsening of dietary habits, coupled with declining levels of physical activity among the population, with negative consequences on body composition and overall health $[20,56,59]$. These changes are contributing to a global increase in the prevalence of non-communicable diseases [57, 60]. Therefore, the inclusion of WC and WHtR within health monitoring systems is justifiable and has been recommended $[8,10]$. Schools may be an ideal setting in which to monitor levels of fitness [61] and to formulate and apply specific strategies to promote young people's future health.

This study has certain limitations. First, it included participants from only one region in Colombia; therefore, caution is needed in extrapolating these findings to all Colombian children and adolescents. Second, we did not examine the potential impact of recognised determinants such as socio-economic factors, diet, patterns of physical activity and ethnic factors, which could modulate the growth and levels of body fat. Third, the study population was composed of young people at statefunded schools in a single city; therefore, the data obtained are not fully representative of the population of Bogotá or of Colombia. However, this city is the largest in the country, and is home to $15 \%$ of its population. It includes a mix of locally-born residents and those arriving from other regions, and so it is racially and culturally diverse. Another limitation is that the study did not evaluate students attending private schools. This restriction arose because the study was conducted in collaboration with the Bogotá District Education Department, which only has jurisdiction among public schools. However, $85 \%$ of school-age children are enrolled in the city's public school system. Nevertheless, extrapolation of our findings to all children and adolescents in Bogotá or in Colombia requires caution. Future population-based studies incorporating data for nationally representative samples, such as the one recently conducted in Argentina, are still needed in Colombia and in other countries in the region [42-46]. This is an area in which further research is needed. However, the above-noted limitations do not invalidate the results obtained.

This study also has strengths that should be emphasised. The percentile values presented, based on a large, newly-compiled population sample, are the first to be obtained for WC and WHtR in Colombian children and adolescents. The results obtained enable us to make an accurate description of the anthropometric characteristics of the population studied and to highlight their age and gender-related variations. These percentiles can be used as a benchmark with which to compare the body composition of individuals of a corresponding age in the city, country and region.

\section{Conclusions}

In conclusion, this is the first comprehensive study to present smoothed age and sex-specific WC and WHtR percentiles for Colombian children and adolescents aged 9.0-17.9 years. Both parameters present high sensitivity and specificity as predictors of overweight and obesity among the study population. The growth charts obtained will enable healthcare workers and researchers to diagnose and monitor children and adolescents, and could be used for the early detection of obesity.

\section{Abbreviations \\ AUC: Area under the receiver-operating characteristic curves; BMI: Body mass index; BW: Body weight; FUPRECOL: Asociación de la fuerza prensil con manifestaciones de riesgo cardiovascular tempranas en niños y adolescentes colombianos (Association between grip strength and early signs of cardiovascular risk in Colombian children and adolescents); Ht: Height; IOTF: International Obesity Task Force; ISAK: International Society for the Advancement of Kinanthropometry; ROC: Receiver operating characteristics curve; SD: Standard deviation; TEM: Technical error of measurement; USA: United States of America; WC: Waist circumference; WHtR: Waist-to- height ratio}

\section{Acknowledgements}

The authors are grateful to the Bogotá District Education Secretary for facilitating the data used in this study. The authors also thank the participating students, staff and schools in Bogotá District. We would like to thank Javier Martínez-Torres for providing her qualitative work and data analysis.

\section{Funding}

The FUPRECOL Study was carried out with financial support from Instituto Colombiano para el Desarrollo de la Ciencia y la Tecnología "Francisco José de Caldas" COLCIENCIAS (Contract N 671-2014 Code 122265743978).

\section{Availability of data and materials}

The study data are subject to legal and ethical restrictions imposed by the authors' IRB (Universidad del Rosario, Bogotá), as the sample population was composed of children and adolescents at public schools in Colombia (Act No. 1581, October 2012 and National Decree No. 1377-2013). Available at: https://goo.gl/JbLBl and https://goo.gl/aaBOyL

Contact for the raw data.

Study details of data access / requests: Robinson Ramirez-Velez. (robinson.ramirez@urosario.edu.co).

References (for data access arrangements).

1. Universidad del Rosario [computer file]. Bogotá, Colombia: USTA data archive [distributor], may 2015. "Fuprecol study" (in Spanish). 


\section{Authors' contributions}

RRV and JM-T conceptualised the study, drafted the manuscript and take responsibility for the integrity of data handling and the accuracy of the statistical analysis. JM-J, EGJ, JSRV, JFME, KGR, RRV, FL, JECB, and AG-H contributed to the study conception and design, data interpretation, critica review of the manuscript, and study supervision. All authors read and approved the final manuscript

\section{Ethics approval and consent to participate}

The Review Committee for Research on Human Subjects at Universidad del Rosario (Bogotá, Colombia) [Code CEI-ABN026-000262] approved all of the study procedures. At the beginning of the study, written informed consent was obtained from all participants as well as the parents or guardians of all minors (subjects under 18 years of age) enrolled in the study. All participants as well as parents/guardians had been previously informed of the research objectives and protocols. Participants were assured that participation was voluntary and that the information provided would be kept anonymous and strictly confidential. This research was performed in strict compliancewith the International Code of Medical Ethics established by the World Medical Association, the Declaration of Helsinki and with current Colombian laws governing clinical research on human subjects (Resolution 008430/1993 Ministry of Health)

\section{Consent for publication}

In every case, written informed consent was provided by the participant's parent or guardian. In addition, each participant gave verbal assent. The Ethics Committee of the University of Rosario, which is recognised by the Colombian National Ethics Committee, provided ethical approval.

\section{Competing interests}

The authors declare that they have no competing interests.

\section{Publisher's Note}

Springer Nature remains neutral with regard to jurisdictional claims in published maps and institutional affiliations.

\section{Author details \\ ${ }^{1}$ Centro de Estudios para la Medición de la Actividad Física (CEMA). Escuela de Medicina y Ciencias de la Salud, Universidad del Rosario, Cra. 24 No. 63C 69, Bogotá D.C, Colombia. ${ }^{2}$ Grupo de Ejercicio Físico y Deportes, Facultad de Salud, Vicerrectoría de Investigaciones, Universidad Manuela Beltrán, Bogotá D.C, Colombia. ${ }^{3}$ Departamento de Enfermería, Facultad de Ciencias de la Salud, Universidad de Granada, Avda. De la llustración, s/n, 18016 Granada, Spain. ${ }^{4}$ Grupo CTS-436: Centro de Investigación Mente, Cerebro y Comportamiento (CIMCYC), Granada, Spain. ${ }^{5}$ Hubert Department of Global Health, Rollins School of Public Health, Emory University, Atlanta, GA, USA. ${ }^{6}$ Laboratorio de Ciencias de la Actividad Física, el Deporte y la Salud, Facultad de Ciencias Médicas, Universidad de Santiago de Chile, USACH, Santiago, Chile.}

Received: 20 April 2016 Accepted: 3 July 2017

Published online: 11 July 2017

\section{References}

1. Selassie M, Sinha AC. The epidemiology and aetiology of obesity: a global challenge. Best Pract Res Clin Anaesthesiol. 2011;25:1-9.

2. Von Eyben FE, Mouritsen E, Holm J, Montvilas P. Dimcevski G, Suciu G, Helleberg I, Kristensen L, von Eyben R. Intra-abdominal obesity and metabolic risk factors: a study of young adults. Int J Obes. 2003;27:941-9.

3. Kagawa M, Byrne NM, Hills AP. Comparison of body fat estimation using waist:height ratio using different 'waist' measurements in Australian adults. Br J Nutr. 2008;100(5):1135-41.

4. Despres JP. Body fat distribution and risk of cardiovascular disease: an update. Circulation. 2012:126(10):1301-13.

5. Expert Panel on Detection, Evaluation, and Treatment of High Blood Cholesterol in Adults. Executive Summary of The Third Report of The National Cholesterol Education Program (NCEP) Expert Panel on Detection, Evaluation, And Treatment of High Blood Cholesterol In Adults (Adult Treatment Panel III). JAMA 2001;285:2486-2497.
6. World Health Organization. Obesity: Preventing and Managing the Global Epidemic. Report of a WHO Consultation on Obesity, 3-5 June 1997, Geneva, WHO/NUT/NCD/98.1. Geneva: WHO, 1997.

7. Kaur JA. Comprehensive review on metabolic syndrome. Cardiol Res Pract. 2014;2014:943162.

8. Ashwell M, Mayhew L, Richardson J, Rickayzen B. Waist-to-height ratio is more predictive of years of life lost than body mass index. PLoS One. 2014;9(9):e103483.

9. González-Ruíz K, Correa-Bautista JE, Ramírez-Vélez R. Evaluation of the body adiposity index in predicting percentage body fat among Colombian adults. Nutr Hosp. 2015;32(1):55-60.

10. Ashwell M, Gunn P, Gibson S. Waist-to-height ratio is a better screening tool than waist circumference and BMI for adult cardiometabolic risk factors: systematic review and meta-analysis. Obes Rev. 2012;13(3):275-86.

11. Carmienke S, Freitag MH, Pischon T, Schlattmann P, Fankhaenel T, Goebel H, Gensichen J. General and abdominal obesity parameters and their combination in relation to mortality: a systematic review and metaregression analysis. Eur J Clin Nutr. 2013;67(6):573-85.

12. Browning LM, Hsieh SD, Ashwell M. A systematic review of waist-to-height ratio as a screening tool for the prediction of cardiovascular disease and diabetes: 0.5 could be a suitable global boundary value. Nutr Res Rev. 2010;23(2):247-69.

13. Lee CM, Huxley RR, Wildman RP, Woodward M. Indices of abdominal obesity are better discriminators of cardiovascular risk factors than BMI: a meta-analysis. J Clin Epidemiol. 2008;61 (7):646-53.

14. Alberti KGMM, Zimmet P, Shaw J. The metabolic syndrome - a new worldwide definition. Lancet. 2005:366:1059-62.

15. Hsieh SD, Yoshinaga H, Muto T. Waist-to-height ratio, a simple and practical index for assessing central fat distribution and metabolic risk in Japanese men and women. Int J Obes. 2003:27:610-6.

16. Bosy-Westphal A, Geisler C, Onur S, Korth O, Selberg O, Schrezenmeir J, Muller MJ. Value of body fat mass vs anthropometric obesity indices in the assessment of metabolic risk factors. Int J Obes. 2006;30:475-83.

17. Sakurai M, Miura K, Takamura T, Ota T, Ishizaki M, Morikawa Y, Kido T. Naruse $Y$ \& Nakagawa. Gender differences in the association between anthropometric indices of obesity and blood pressure in Japanese. Hypertens Res. 2006;29:75-80.

18. Ramírez-Vélez R, Tordecilla-Sanders A, Correa-Bautista JE, Peterson MD, Garcia-Hermoso A. Handgrip Strength and Ideal Cardiovascular Health among Colombian Children and Adolescents. J Pediatr. 2016;179:82-89.e.

19. Sarmiento OL, Ramirez A, Kutschbach BS, Pinzón PL, García S, Olarte AC, Mosquera T, Atalah E, Ojeda G, Forero Y. Nutrition in Colombian pregnant women. Public Health Nutr. 2012;15:955-63.

20. Ramírez-Vélez R, Rodrigues-Bezerra D, Correa-Bautista JE, Izquierdo M, Lobelo F. Reliability of health-related physical fitness tests among Colombian children and adolescents: the FUPRECOL study. PLoS One. 2015:10(10):e0140875

21. Lin JS, Lee LT, Chen CY, Lo H, Hsia HH, Liu IL, Lin RS, Shau WY, Huang KC. Optimal cut-off values for obesity: using simple anthropometric indices to predict cardiovascular risk factors in Taiwan. Int J Obes. 2002;26:1232-8.

22. Ho SY, Lam TH, Janus ED. Waist to stature ratio is more strongly associated with cardiovascular risk factors than other simple anthropometric indices. Ann Epidemiol. 2003;13:683-91.

23. Hsieh SD, Muto T. Metabolic syndrome in Japanese men and women with special reference to the anthropometric criteria for the assessment of obesity: proposal to use the waist-to-height ratio. Prev Med. 2006;42:135-9.

24. Park SH, Choi SJ, Lee KS, Park HY. Waist circumference and waist-to-height ratio as predictors of cardiovascular disease risk in Korean adults. Circ J. 2009;73(9):1643-50.

25. Can AS, Yildiz EA, Samur G, Rakicioğlu N, Pekcan G, Ozbayrakçi S, Palaoğlu KE, Gönen M, Bersot TP. Optimal waist:height ratio cut-off point for cardiometabolic risk factors in Turkish adults. Public Health Nutr. 2010;13(4):488-95

26. Zeng $Q$, He Y, Dong S, Zhao X, Chen Z, Song Z, Chang G, Yang F, Wang Y. Optimal cut-off values of BMl, waist circumference and waistheight ratio for defining obesity in Chinese adults. Br J Nutr. 2014;112(10):1735-44.

27. Aguilar de Plata AC, Pradilla A, Mosquera M, Gracia de Ramírez AB, Ortega JG, Ramírez-Vélez R. Centile values for anthropometric variables in Colombian adolescents. Endocrinol Nutr. 2011;58(1):16-23.

28. Rodríguez-Bautista YP, Correa-Bautista JE, González-Jiménez E, SchmidtRioValle J, Ramírez-Vélez R. Values of waist/hip ratio among children and 
adolescents from Bogotá, Colombia: the FUPRECOL study. Nutr Hosp. 2015;32(5):2054-61.

29. ICBF. Instituto Colombiano de Bienestar Familiar. Encuesta Nacional de la Situación Nutricional en Colombia. (Instituto Colombiano de Bienestar Familiar ICBF, ed.). Bogotá; 2010 https://goo.gl/TTVnVZ.

30. Caicedo-Álvarez JC, Correa-Bautista JE, González-Jiménez E, Schmidt-RioValle J, Ramírez-Vélez R. Waist circumference distribution in Colombian schoolchildren and adolescents: the FUPRECOL study. Endocrinol Nutr. 2016;63(6):265-73.

31. Departamento Administrativo Nacional de Estadística (DANE). Los grupos étnicos de Colombia en el censo de 2005. Análisis de Resultados. Bogotá, Colombia, 2007.

32. Marfell-Jones M, Olds T, Stewart A. International standards for anthropometric assessment. ISAK: Potchefstroom, South Africa; 2006.

33. Cole TJ, Bellizzi MC, Flegal KM, Dietz WH. Establishing a standard definition for child overweight and obesity worldwide: international survey. BMJ. 2000:320:1240-3.

34. Wijnhoven TM, van Raaij JM, Spinelli A, Rito Al, Hovengen R, Kunesova M, Starc G, Rutter H, Sjöberg A, Petrauskiene A, O'Dwyer U, Petrova S, Farrugia Sant'angelo V, Wauters M, Yngve A, Rubana IM, Breda J. WHO European childhood obesity surveillance initiative 2008: weight, height and body mass index in 6-9-year-old children. Pediatr Obes. 2013;8(2):79-97.

35. Cadenas-Sanchez C, Nyström C, Sanchez-Delgado G, Martinez-Tellez B, Mora-Gonzalez J, Risinger AS, Ruiz JR, Ortega FB, Löf M. Prevalence of overweight/obesity and fitness level in preschool children from the north compared with the south of Europe: an exploration with two countries. Pediatr Obes. 2016;11(5):403-10.

36. Cousminer DL, Widén E, Palmert MR. The genetics of pubertal timing in the general population: recent advances and evidence for sex-specificity. Curr Opin Endocrinol Diabetes Obes. 2016;23(1):57-65.

37. Grivas TB, Mihas C, Arapaki A, Vasiliadis E. Correlation of foot length with height and weight in school age children. J Forensic Legal Med. 2008;15(2):89-95.

38. Zúñiga J, Housh TJ, Mielke M, Hendrix CR, Camic CL, Johnson GO, Housh DJ, Schmidt RJ. Comparaciones de género de antropométricos características de jóvenes nadadores sprint. J Strength Cond Res. 2011;25(1):103-8

39. Musa DI, Toriola AL, Monyeki MA, Lawal B. Prevalence of childhood and adolescent overweight and obesity in Benue state. Nigeria Trop Med Int Health. 2012:17(11):1369-75.

40. Patsopoulou A, Tsimtsiou Z, Katsioulis A, Rachiotis G, Malissiova E, Hadjichristodoulou C. Prevalence and risk factors of overweight and obesity among adolescents and their parents in central Greece (FETA Project). Int J Environ Res Public Health. 2015;13(1). pii: E83.

41. Ouyang X, Lou Q, Gu L, Ko GT, Mo Y, Wu H, Bian R. Anthropometric parameters and their associations with cardio-metabolic risk in Chinese working population. Diabetol Metab Syndr. 2015;7:37.

42. Hirschler V, Molinari C, Maccallini G, Hidalgo M, Gonzalez C. Waist circumference percentiles in indigenous Argentinean school children living at high altitudes. Child Obes. 2015;24 doi:10.1089/chi.2015.0058.

43. Ma L, Cai L, Deng L, Zhu Y, Ma J, Jing J, Chen Y. Waist circumference is better than other anthropometric indices for predicting cardiovascular disease risk factors in Chinese children - a cross-sectional study in Guangzhou. J Atheroscler Thromb. 2016;23(3):320-9.

44. Gracia-Marco L, Moreno LA, Ruiz JR, Ortega FB, de Moraes AC, Gottrand F, Roccaldo R, Marcos A, Gómez-Martínez S, Dallongeville J, Kafatos A, Molnar D, Bueno G, de Henauw S, Widhalm K, Wells JC. Body composition indices and single and clustered cardiovascular disease risk factors in adolescents: providing clinical-based cut-points. Prog Cardiovasc Dis. 2016;58(5):555-64.

45. Mushtaq MU, Gull S, Abdullah HM, Shahid U, Shad MA, Akram J. Waist circumference, waist-hip ratio and waist-height ratio percentiles and central obesity among Pakistani children aged five to twelve years. BMC Pediatr. 2011;11:105

46. Bamoshmoosh M, Massetti L, Aklan H, Al-Karewany M, Goshae HA, Modesti PA. Central obesity in Yemeni children: a population based cross-sectional study. World J Cardiol. 2013;5(8):295-304.

47. Wang JJ, Wang HJ, Liu JS, Ma J. The association between body mass index, waist circumference with body fat percent, and abdominal fat rate in overweight and obese pupils. Zhonghua Yu Fang Yi Xue Za Zhi. 2013:47(7):603-7.
48. Smith SC Jr, Haslam D. Abdominal obesity, waist circumference and cardiometabolic risk: awareness among primary care physicians, the general population and patients at risk-the shape of the nations survey. Curr Med Res Opin. 2007:23:29-47.

49. Brambilla P, Bedogni G, Moreno LA, Goran MI, Gutin B, Fox KR, Peters DM, Barbeau P, De Simone M, Pietrobelli A. Crossvalidation of anthropometry against magnetic resonance imaging for the assessment of visceral and subcutaneous adipose tissue in children. Int J Obes. 2006;30:23-30.

50. Cattaneo A, Monasta L, Stamatakis E, Lioret S, Castetbon K, Frenken F, Manios Y, Moschonis G, Savva S, Zaborskis A, Rito Al, Nanu M, Vignerová J, Caroli M, Ludvigsson J, Koch FS, Serra-Majem L, Szponar L, van Lenthe F, Brug J. Overweight and obesity in infants and pre-school children in the European Union: a review of existing data. Obes Rev. 2010;11:389-98.

51. Palmer BF, Clegg DJ. The sexual dimorphism of obesity. Mol Cell Endocrinol. 2015:402:113-9.

52. Filho VC, Lopes Ada S, Fagundes RR, de Campos W. Anthropometric indices among schoolchildren from a municipality in southern Brazil: a descriptive analysis using the LMS method. Rev Paul Pediatr. 2014;32(4):333-41.

53. Bacopoulou F, Efthymiou V, Landis G, Rentoumis A, Chrousos GP. Waist circumference, waist-to-hip ratio and waist-to-height ratio reference percentiles for abdominal obesity among Greek adolescents. BMC Pediatr. 2015;15:50.

54. Fredriks AM, van Buuren S, Fekkes M, Verloove-Vanhorick SP, Wit JM. Are age references for waist circumference, hip circumference and waist-hip ratio in Dutch children useful in clinical practice. Eur J Pediatr. 2005:164(4):216-22.

55. Schwandt $P$, Kelishadi $R$, Haas GM. First reference curves of waist circumference for German children in comparison to international values: the PEP family heart study. World J Pediatr. 2008;4(4):259-66.

56. Aeberli I, Gut-Knabenhans I, Kusche-Ammann RS, Molinari L, Zimmermann MB. Waist circumference and waist-to-height ratio percentiles in a nationally representative sample of 6-13 year old children in Switzerland. Swiss Med Wkly. 2011;141:w13227.

57. Ortega FB, Silventoinen $K$, Tynelius $P$, Rasmussen $F$. Muscular strength in male adolescents and premature death: cohort study of one million participants. BMJ. 2012;345:e7279.

58. Ekelund U, Anderssen SA, Froberg K, Sardinha LB, Andersen LB, Brage S. Independent associations of physical activity and cardiorespiratory fitness with metabolic risk factors in children: the European youth heart study. Diabetologia. 2007;50:1832-40.

59. Parra DC, lannotti L, Gomez LF, Pachón H, Haire-Joshu D, Sarmiento OL, Kuhlmann AS, Brownson RC. The nutrition transition in Colombia over a decade: a novel household classification system of anthropometric measures. Arch Public Health. 2015;73(1):12.

60. González SA, Castiblanco MA, Arias-Gómez LF, Martinez-Ospina A, Cohen DD, Holguin GA, Almanza A, Lemos DM, Correa-Bautista JE, Escobar ID, García J, Gámez R, Garzon M, Beltrán YH, Hurtado H, Lozano O, Páez DC, Ramírez-Vélez R, Ruiz N, Tovar G, Sarmiento OL. Results from Colombia's 2016 report card on physical activity for children and youth. J Phys Act Health. 2016;13(11 Suppl 2):S129-36.

61. De Miguel-Etayo P, Gracia-Marco L, Ortega FB, Intemann T, Foraita R, Lissner $L$, et al. Physical fitness reference standards in European children: the IDEFICS study. Int J Obes. 2014;38(Suppl 2):57-66.

\section{Submit your next manuscript to BioMed Central and we will help you at every step:}

- We accept pre-submission inquiries

- Our selector tool helps you to find the most relevant journal

- We provide round the clock customer support

- Convenient online submission

- Thorough peer review

- Inclusion in PubMed and all major indexing services

- Maximum visibility for your research

Submit your manuscript at www.biomedcentral.com/submit
Biomed Central 